\title{
The acquisition of accent marks in L2 French : The effects of keyboarding and text format
}

\author{
Jessica Sturm \\ Purdue University \\ jsturm@purdue.edu
}

\section{Introduction}

For a language such as French, which is full of a variety of accent marks, the increased use of technology and keyboarding typical of the 21 st century raises the issue of producing accent mark-letter combinations in word-processing software or online in web pages. In American English, using an American keyboard, as the participants of the present study do, typing necessitates use of the QWERTY alphanumeric section of the keyboard. One keystroke = one letter, with the exception of the SHIFT key to make capital letters. Not only are accented letters not present in English, they are not present or represented on the keyboard. In order to make an accented letter, a combination of keystrokes must be pressed, consecutively and concurrently, or the "Insert Symbols" dialogue box must be employed. In this way, typing accented letters in French presents a challenge for L1 English learners. The present research aims to understand the effects of 1) typing methods in comparison with handwriting and 2) text format (word list or paragraph) on learners' acquisition of accent marks in L2 French, in light of previous research in memory, typing, L2 orthography, attention/awareness/noticing, and possible connections between psychomotor movement and learning.

\section{Review of Previous Research}

\subsection{Memory and Encoding}

Tulving (2000) explains the role of encoding as the process by which information is put into memory, recoded or consolidated, and retrieved or recalled when it is needed. The processes of encoding and retrieving information have been widely-discussed among memory researchers for decades. Craik and Lockhart (1972) proposed a "levels of processing" framework, which suggested that processing new material more deeply leads to better and longer recall. "Depth of processing," or the degree to which material is semantically or cognitively analyzed forms the backbone of this framework of memory research. More intricate analysis, therefore, means deeper processing of the material, semantically or cognitively. Retention, according to this framework, is a function of depth, determined by a number of factors. These factors include the amount of attention devoted to the material, its compatibility with the analyzing structures, and the processing time available. The level of processing will influence the rate at which it will be lost; in other words, material more deeply processed will be lost at a slower rate.

From the results of ten experiments exploring the levels-of-processing framework, Craik and Tulving (1975) concluded that mental activity will lead to learning and retention; elaborateness of the encoding will influence memory performance. Craik and Tulving (1975) also suggested "spread", rather than "depth" of encoding as a more appropriate term to describe the process in question.

Postman, Thompson, and Grey (1978) defined spread of encoding as "the elaboration of a stimulus in the course of an encoding operation." (p. 681). Spread of encoding, in other words, refers to the extent to which a stimulus is processed, and thus encoded. They suggest that researchers employ task differing only in respect to the prescribed level of processing, keeping all other aspects constant. All 
participants/conditions being compared should perform the same tasks. The tasks, then, should vary only on condition.

In regards to the present research, Craik and Tulving's (1975) results, by suggesting that the level to which material is encoded plays a role in one's ability to learn the material, supports the idea that typing, rather than handwriting, words bearing accents marks may help the learner retain the accent marks. Typing an accent mark necessitates extra keystrokes outside the normal range of the keyboard for an American whose L1 is English; these extra keystrokes, which require additional attention to make, could be said to encode the material more elaborately than handwriting them.

\subsection{Attention, Awareness, and Noticing}

Schmidt and Frota (1986), first proposed a "conscious notice-the-gap principle" (p. 313) that suggests that a learner must recognize the difference between his/her nontargetlike form and the target form of the L2 in order to acquire it. (Schmidt and Frota, $1986: 311$ ). This discovery has led to a model of attention and awareness in language learning, considered "necessary to understand virtually every aspect of second language acquisition" (Schmidt, 2001: 3). This model involves consciousness, which ties together attention, short term memory, controlled vs. automatic processing, and serial vs. parallel processing (Schmidt, 1990); attention as the process of encoding language input and keeping it active (Robinson, 2003); and noticing as both conscious registering of some event (Schmidt, 1995) and detection with awareness and rehearsal in short-term memory (Robinson, 1995). In regards to the present study, this theory suggests that the participants' attention must be drawn to the accent marks on L2 French words in order for acquisition (defined as the ability to recognize correctly accented words, and to place accent marks accurately on a dictation task) to occur.

\section{$2.3 \quad$ Typing}

Typing, a learned skill, is a mental and physical process. Cooper (1983) addresses the psychology of typing, describing an information-flow module that is similar to John's (1996) TYPIST model : character recognition ${ }^{1}$, short-term storage buffer $^{2}$, motor program ${ }^{3}$, keystroke, and sensory feedback ${ }^{4}$, overseen by an executive pacer". He also mentions that "touch typewriting is form of motor behavior that requires extensive periods of training" (p. 20). In regards to the present study, it should be recalled that not only is typing a skill that requires specific training, but is, under normal circumstances, taught later than printing or writing by hand.

\section{$2.4 \quad$ Typing and Irregular Orthography}

For native Anglophone learners of French, the typing process in French would be expected to be different, due to the need for insertion of accents over letters, which, on an American keyboard, will require typing outside the normal QWERTY section of the keyboard. This leaves the question of how much difference and how is this difference manifested? How do learners engage in typing with unfamiliar orthography?

Bloemsaat, Van Galen, and Meulenbroek (2003) found that irregular orthography slowed participants' typing speed. Subjects showed a significant (28\%) increase in time interval between target sequences of two words when the second word was orthographically irregular. Bloemsaat et al. (2003) found a significant interaction between orthographic irregularity and memory load. They suggest that the increased interval time "...would ... reflect changes of one or more of the processes involved in transcription typing." (p. 130). For learners whose L1, such as English, does not include accent marks, accent marks in the L2 (such as French), would constitute irregular orthography, and the typing process would be expected to be different from L1 to L2; following Bloemsaat et al. (2003), it would be slower 
and incur an increased memory load. In this study, the amount of difference will be measured in number of keystrokes to produce a letter, and controlled by assigning typing methods to each typing group.

\subsection{More Movement $=$ Better Learning}

Gascoigne-Lally (2000) found that university students (first-semester L2 French) who typed a passage in French had better recall of the diacritics in the passage when they heard it as a dictation exercise than those who wrote out the same passage by hand. She suggested, post-hoc, that the extra psychomotor movement in typing might be behind this increased recall : “...the additional key combinations and psycho-motor steps required in the experimental condition implicitly increased the saliency of the accents during encoding" (Gascoigne-Lally, 2000 : 903).

Gascoigne (2006b) replicated Gascoigne-Lally (2000) with a few minor changes. First, the control (handwriting) group was reminded of the importance of accent marks in French orthography, to "compensate for the potential effect that the list of key combination codes may have had on reminding the experimental group of ... the importance of accents in French." (Gascoigne, 2006b : 153). Second, a follow-up questionnaire assessing participants' perceived difficulty in completing the copying task and their preference or comfort typing and writing in their L1 (English) and L2 (French) was administered post-treatment. Third, an extra prepositional phrase was added to the paragraph used by Gascoigne-Lally (2000). Gascoigne (2006b) found, like Gascoigne-Lally (2000), that participants in the computer group produced "significantly higher diacritic recall scores ... than those in the pen-and-paper control group" (p.155), using a t-test at the .05 level. However, students in both groups preferred composing on a computer in English and using pen and paper in French.

Gascoigne (2006a), a replication of Gascoigne (2000b) that included learners of both L2 French and L2 Spanish, found that participants who typed target items, in either language, performed significantly better than those who copied the targets by hand. Students of both languages unanimously preferred to compose in their L2 with pen and paper, while preferring to compose on a computer in their L1.

From Gascoigne's $(2000,2006 \mathrm{a}, \mathrm{b})$ results, she posited that it was the extra psychomotor steps involved in typing that caused the improved recall. The results of these three studies strongly support the idea that typing leads to better retention of L2 accent marks, even though students prefer to compose with pen and paper in the L2. Students' preference for writing with pen and paper in the L2 also highlights the difficulty presented to L2 learners of a language that features accent marks.

Heift (2003) found that students of L2 German who clicked on multiple-choice answers were significantly less successful at acquiring sentence structure than students who had practiced sentence structure by typing the sentence or dragging and dropping parts of the sentence. However, there was no significant difference observed between typing and dragging/dropping. Heift (2003) noted that the students in the typing and dragging conditions made more errors during treatment than the clicking. Both the nature of their treatment condition and their increased number of mistakes suggest that the typing and dragging groups had more psychomotor movement involved in their treatment condition, supporting Gascoigne's $(2000,2006 a, b)$ post-hoc hypothesis that extra psychomotor movement leads to increased learning.

Sturm and Golato (in press) tested Gascoigne's (2000, 2006a, b) post-hoc hypothesis that extra psychomotor movement, defined as movement related to previously unknown information, such as the spelling of new words in an L2, led to better learning by looking at two keyboarding conditions (one using preprogrammed function keys, one using alt+ numeric codes), along with a handwriting condition. Psychomotor movement was quantified between the two typing groups : the function keys group used one keystroke to make accented letters, while the alt + codes group was required to hold one key while making four additional keystrokes. Participants practiced a list of target items one of three ways: typing, 
using alt+numeric codes to make accented letters; typing, using pre-programmed function keys to make accented letters, or writing by hand. Results indicated no significant difference between groups on dictation posttests, and on each measure there was considerable within-group variance in scores. Therefore, Sturm and Golato (in press) were not able to conclude that practice condition (hand writing, simple keyboarding, or extended keyboarding) had a significant effect on the acquisition of French accent marks. This is in direct contradiction of the results obtained by Gascoigne-Lally (2000). Sturm and Golato (in press) noted that while they had asked participants to practice words in a list, Gascoigne-Lally (2000) had asked her participants to practice a paragraph, adapted from a beginning textbook (C. Gascoigne, personal communication, October 21, 2003).

Sturm (2006) investigated the effect of presentation format along with keyboarding vs. handwriting on the recall of accents in L2 learners of French; participants $(n=16)$ were asked to copy Gascoigne-Lally's (2000) paragraph along with target items chosen for the study in both word list and paragraph form. She found, as did Sturm and Golato (in press) considerable variance within groups and was therefore unable to conclude that there was a significant effect of practice mode on ability to recall accent marks. Her results, however, did reveal that there was a significant difference between the presentation formats and between word sets, with participants scoring better on Gascoigne-Lally's (2000) words than the words she chose for the study, and better on the latter word set in word list format than in paragraph format. It is particularly interesting that participants scored higher on Gascoigne-Lally's (2000) paragraph, considering that participants were exposed to Sturm's (2006) words twice (once as a paragraph and once as a list), while they were only exposed to Gascoigne-Lally's words once.

\section{$2.6 \quad$ List vs. paragraph}

The major difference between Gascoigne (2000, 2006a, b) and Sturm and Golato (in press) is the use of a paragraph for the practice of target items (Gascoigne) and the use of a word list (Sturm and Golato). Previous studies looking specifically at spelling recall, such as Cunningham and Stanovich (1990) and Vaughn, Schumm, and Gordon. (1993) used a list format as well. Sturm (2006) used both, but had all participants practice the words chosen for her study in both forms.

Sentence/passage format may facilitate recall in all conditions; according to Craik and Lockhart (1972), "if the words form a meaningful sentence ... they are compatible with deeper learned structures and larger units may be dealt with ... we rehearse a sound, an idea, or an image in the same way that we perceive objects and not constellations of attributes" (p. 679).

Schneider, Healy, Ericsson, and Bourne (1995) and Schneider, Healy, and Bourne (1998) suggest that, while a simpler task facilitates learning, long-term retention is aided by the information being presented in a more complex task. Contextual interference may be necessary to long-term retention; as they claim, "items that have more contextual interference require more processing and are thus learned more slowly, but if well learned initially they will be retained as well as or better than the low-interference items." (Schneider et al., 1998 : 77). In regards to the present research, items which are practiced in a paragraph may have contextual interference, while items practiced in a word list would have no such interference. According to their results, then, a person who practices words in a paragraph will have better long-term retention of the material than a person who practices the same words in a word list.

Coniam (1998) discusses the "importance of listening centering on a coherent text, rather than short listening fragments" (p. 35). He argues that a listening task based on a complete text rather than short fragments is more authentic; in his argument, he compares dialogue fragments to an intact paragraph. Certainly, a word list is considerably more fragmented than a dialogue. Learners in Gascoigne's (2000, 2006a, b) as Sturm's (2006) and Sturm and Golato's (in press) studies were required to complete a dictation task, which involves listening comprehension and reaction in the form of writing what one hears. 
The authenticity of a paragraph dictation (Gascoigne 2000, 2006a, b) can be said to be superior to a list dictation (Sturm and Golato, in press).

\section{$3 \quad$ Research Questions}

What is the effect of

1a. typing accented words rather writing them by hand

1b. the number of keystrokes used to type an accented letter

2. the format of presentation (list vs. paragraph form)

on the acquisition of diacritic marks in L2 learners of French?

These research questions are designed to test the following hypotheses:

(1a) Participants who practice accented French target items by typing them will be better able to place the accents in dictation posttests and recognize correctly placed accents better in recognition posttests than participants who practice them by hand. This is suggested by the results of Gascoigne (2000, 2006a, b).

(1b) Participants who practice accented French target items by typing and using multiple keystrokes to make accented letters will be better able to place the accents in dictation posttests and recognize correctly placed accents better in recognition posttests than participants who practice them by typing and using a single keystroke to make accented letters. This is suggested by the results of Gascoigne $(2000,2006 \mathrm{a}, \mathrm{b})$ and Heift (2003).

(2) Participants who practice and are tested on the target items in paragraph form will correctly place accent marks on dictation posttests and will recognize correctly accented words in recognition posttests less successfully than those who practice and are tested on target items in word list form. This is suggested by Schneider, Healy, and Bourne (1998), in that a paragraph would provide "contextual interference".

\section{$4 \quad$ Methodology}

\subsection{Participants}

Participants $(n=133)$ were students at a large Midwestern university, L1 English, enrolled in French 101, who were true beginners in French.. A biographical questionnaire was administered at the time of recruitment in order to verify these factors. Participants were awarded extra credit in French class for their participation; the extra credit was contingent upon attendance at all class sessions and completion of all tasks.

Fifty-seven of these 133 participants were excluded for the following reasons : being non-native speakers of English or native bilinguals $(n=10)$; having already studied French $(n=9)$; or missing one or more days on which activities related to the study took place $(n=38)$, which reduced the final group to $n=76$. Participants were divided into six groups; first by treatment group and then by presentation format. The groups' populations are as follows: function keys/word list $n=14$; function keys/paragraph $n=13$; alt+codes/word list $n=10$; alt+codes/paragraph $n=15$; handwriting/word list $n=12$; and handwriting/paragraph $n=12$. 


\subsection{Testing Materials}

Participants were asked to complete several tasks, based on three sets of target items: an introduction to accent marks; a recognition pretest; exposure to target items; an online typing test; copying the target items for practice; and an immediate posttest and delayed posttest, both consisting of a recognition task and a dictation task. The first set of target items is the paragraph used by Gascoigne-Lally (2000, p. 904) (target words and distracters bolded):

Bonjour. Je m'appelle André. Je suis algérien. J'adore le théâtre, la télévision, et l'opéra. Voilà Joëlle, une copine sénégalaise, et son ami Frédéric. Frédéric est français et il habite à Paris.

The second was a word list similar to that used by Sturm and Golato (in press):

$\begin{array}{llllll}\text { garçon } & \text { champs } & \text { reçu } & \text { midi } & \text { blé } & \text { bol } \\ \text { fée } & \text { lit } & \text { grève } & \text { conte } & \text { lèvres } & \text { journal }\end{array}$

The third was the items from the above word list, in paragraph form (target items and distracters bolded).

Le garçon quitte son lit et s'habille. Le match commence avant midi. Comme il y a une grève de la $S N C F$, il prend le bus. Il lit un conte de fée et le journal. Il regarde les champs de blé. Il prend une boisson dans un bol. La boisson est chaude et lui donne mal aux lèvres. Il prend son reçu et il part.

In total, there were 17 target items; the name "Joëlle" was excluded due to the letter/accent combination "ë" being left out of the instruction sheet for the function keys group. Word frequency for the word list and corresponding paragraph was measured by taking target words from Vis-à-vis, 3rd/4th ed. (Amon, Muyskens, and Omaggio Hadley, 2004, 2008). Students were not provided with the meanings of the words chosen for this study, in order to assess only their acquisition of the accent marks, not their ability to learn the word's meaning or use it appropriately.

All students were asked to practice, in addition to the paragraph from Gascoigne-Lally (2000), the words chosen for this research in one of the two formats; six class sections practiced these words in list form $(n=$ $36)$, and the other seven class sections practiced them in paragraph form $(n=40)$. Classes were not randomly assigned to conditions; rather, the goal was to balance group sizes as closely as possible.

From the target items, a recognition task and a dictation task were created. The recognition tasks asked participants to choose the correct spelling of target and distracter items from four choices, which varied only on the presence/absence and correctness of the diacritic, by circling the version of the word that they thought was correct. For example:

garcon garcôn

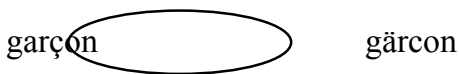

With target items and distracters, there were 27 items on the recognition task. Three forms of the recognition test were created, with the items in a different randomized order on each version. Each group was given each form once.

The dictation task had two forms : one with Gascoigne-Lally's (2000) paragraph and the paragraph created from the words chosen for this study; and the other with Gascoigne-Lally's (2000) paragraph and the list of words chosen for this study. Sections exposed to the words chosen for this study in a word list took the latter version; sections exposed to the same words in paragraph form took the former version. 
Participants listened to the two paragraphs, or the paragraph and word list, read aloud and were instructed to write down what they heard.

\subsection{Procedure}

The experiment took place over the course of eight weeks. Accent marks were presented to all French 101 classes on the day when the pages in the text which introduced accents were scheduled to be covered. The pretest was a recognition task administered in class six weeks after the accent marks were introduced, in order to ensure that all groups had equal knowledge of French accent marks at the outset of the study. After the pretest, the instructor of each class distributed a sheet on which the target items appeared, and read it aloud, after which students repeated the target items. Instructors were asked to do all the reading as students were used to their voices and accents and because instructors would administer the dictation posttests, as was the procedure for Sturm and Golato (in press), Sturm (2006), and Gascoigne (2000, $2006 \mathrm{a}, \mathrm{b})$. This step ensured that participants have a chance to match the visual form of the word with the aural form they will hear on post-practice tests. After each instructor finished reading the items aloud, he or she collected the sheets of paper from the students.

One week after the pretest, participants met in the lab for a regularly-scheduled Internet day. They were then asked to complete a series of tasks; first, an online typing test in English at www.typingtest.com. Participants typed a provided paragraph for one minute and the site provided a gross (words-per-minute) score along with errors and net score.

Two participants scored more than two standard deviations away from the mean $(56.68 \pm[2 \times 14.3705]$; a range of 27.939-85.421); both scores were more than two standard deviations above the mean (87 and 90). One of these participants (90) was in the handwriting group, so his or her typing score would not affect his practice of the accent marks. The participant who scored 87 was in the alt+codes group and was, consequently removed from the subject pool. This left the overall group at $n=75$ and the altcodes/word list group at $n=9$.

Next, participants received sheets of paper with the target items and were asked to copy them, using their assigned practice condition: handwriting, preprogrammed function keys, or alt+numeric codes. The function key group received a list of letter/accent mark combinations, while, the alt-codes group used a similar list that indicated which codes produce which letters. Participants in both groups typed, using MS Word, while their counterparts in the handwriting group used pen and paper. See below for a discussion of scoring.

After participants had finished copying, they turned in the sheet with the target items. Once the entire class had finished, they completed the dictation task. The instructor for each section read the target items (either both paragraphs or Gascoigne-Lally's (2000) paragraph and the word list) aloud four times. After completing the dictation task, participants took a second version of the recognition task.

For the dictation tasks, the maximum score was 22 ; participants were awarded +1 for a correctly placed accent (opéra), +.5 for the wrong accent in the right place (opèra), - .5 for an accent in the wrong place (operà), and -1 for not placing an accent on a word that should have one (opera). The recognition tasks were scored as follows: +1 if they chose the correct version of the word; 0 if they chose any of the other three choices, for a maximum score of 16 .

One week after the lab session and immediate posttest, subjects were given a delayed posttest, which consisted of the dictation task and a different version of the recognition task. The delayed posttest was administered in class by the instructors. No time limit was given for either task. 


\section{$5 \quad$ Results}

The alpha level for all analyses was set at $p=.05$

\section{$5.1 \quad$ Pretests}

The pretest was administered to determine that all treatment groups were equivalent at the outset of the study on their knowledge of accent mark placement in French. A one-way analysis of variance (ANOVA), with treatment/presentation groups as the independent variable showed a significant difference between groups, $F(5,69)=2.39, p=.046$. A series of Tukey HSD post hoc tests revealed a significant difference only between the alt+codes/word list group $(\mathrm{M}=11, \mathrm{SD}=1.87)$ and the handwriting/paragraph group $(\mathrm{M}=8.33, \mathrm{SD}=2.46), p<.05$, Cohen's $d=1.22$. This suggests that the groups were not completely equivalent on their ability to recognize correctly accented words at the outset of the study, and any results will consequently be interpreted with caution. Means are illustrated in Figure 1 below.

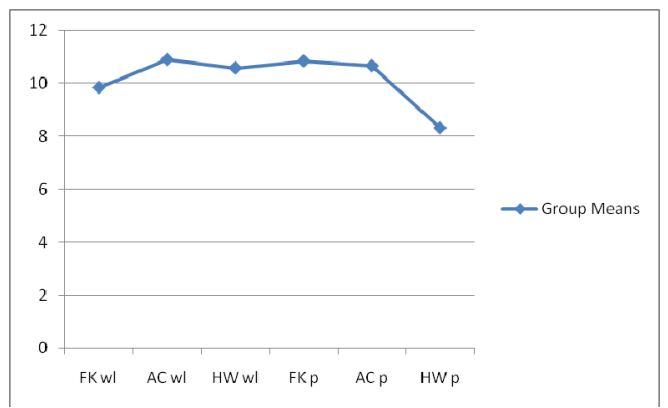

Figure 1. Pretest

\subsection{Immediate Posttest Recognition}

A two-way analysis of variance (ANOVA) on Immediate Posttest Recognition scores revealed a main effect for treatment group (alt+codes $[\mathrm{AC}, \mathrm{M}=13,17, \mathrm{SD}=1.61]$, function keys [FK, $\mathrm{M}=13.70, \mathrm{SD}=$ 1.46], or handwriting [HW, $\mathrm{M}=11.96, \mathrm{SD}=1.81]), F(2,74)=9.68, p=.0002$, Cohen's $d$ (AC vs. HW) $=.71,(\mathrm{FK}$ vs. HW $)=1.06$. There was, however, no main effect for presentation format (word list or paragraph), $F(1,74)=.22, p=.641$. Additionally, the interaction effect was significant, $(F(2,74)=$ $11.31 ; p=.0001)$, suggesting that differences between treatment group means were affected by copying words in either paragraph or word list format. Means are illustrated in Figure 2 below:

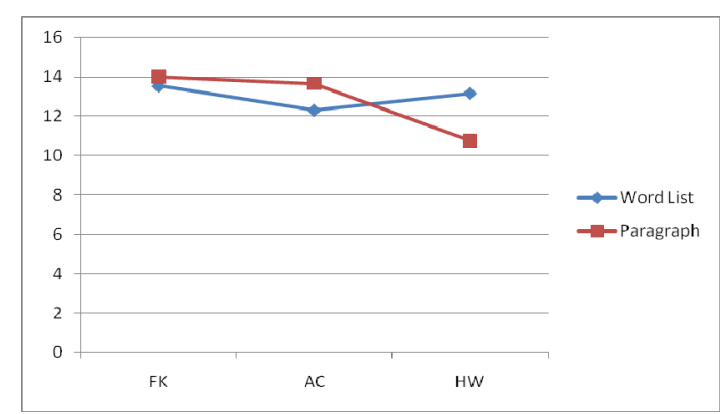

Figure 2. Immediate Posttest Recognition Task 


\subsection{Immediate Posttest Dictation}

A two-way ANOVA of Immediate Posttest Dictation scores revealed no main effect for treatment group $(F(2,74)=2.87, p=064$. . There was, however, a main effect for presentation format $(F(1,74)=5.56, p$ $=.021$, Cohen's $d=.52$; the word list group $(\mathrm{M}=9.186, \mathrm{SD}=8.62)$ outperformed the paragraph group $(\mathrm{M}=4.388, \mathrm{SD}=9.82)$. The interaction effect was also significant, $(F(2,74)=3.28 ; p=.044)$. Values are illustrated below in Figure 3.

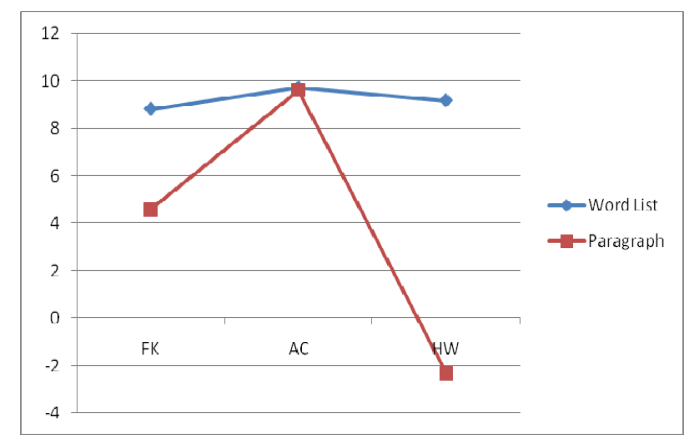

Figure 3. Immediate Posttest Dictation

\subsection{Delayed Posttest Recognition}

A two-way ANOVA of Delayed Posttest Recognition scores revealed a non-significant main effect of both treatment group $(F(2,71)=2.22, p=.117)$ and presentation format $(F(1,71)=.38, p=.540)$. The interaction effect was non-significant, $(F(2,71)=2.72 ; p=.073)$. This suggests that participants' ability to recognize correctly accented words, one week after treatment, by treatment group, was not affected by presentation format. Values are illustrated in Figure 4 below.

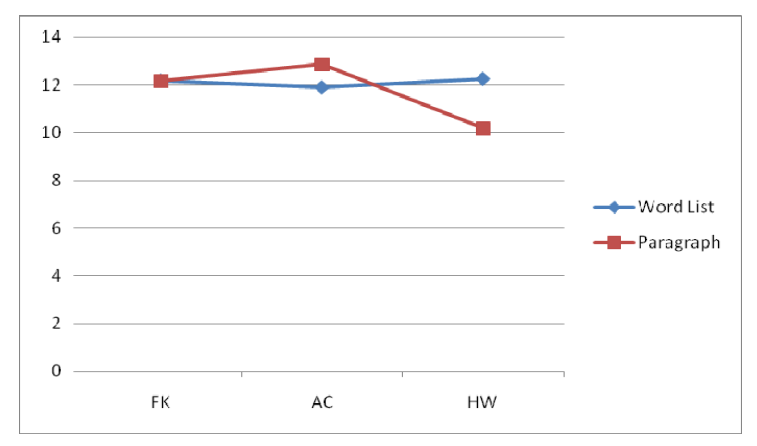

Figure 4. Delayed Posttest Recognition

\subsection{Delayed Posttest Dictation}

A two-way ANOVA of Delayed Posttest Dictation scores reveled a significant main effect of presentation format, $F(1,72)=5.15, p=.027$, Cohen's $d=.53$; the word list group $(\mathrm{M}=6.927, \mathrm{SD}=10.91)$ outperformed the paragraph group $(\mathrm{M}=1.680, \mathrm{SD}=8.58)$. However, the main effect of treatment group 
was non-significant, $F(2,72)=.31, p=.735$. The interaction effect was also non-significant $(F(2,72)=$ $.85 ; p=.432)$. . Values are illustrated in Figure 5 below.

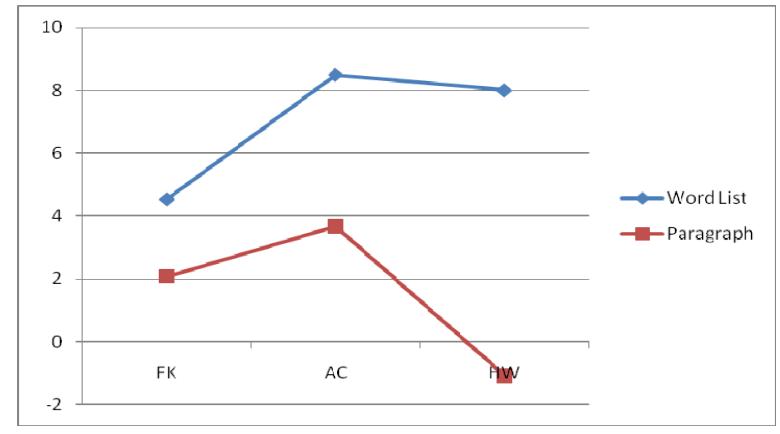

Figure 5. Delayed Posttest Dictation.

\section{$6 \quad$ Discussion and Conclusions}

\subsection{Discussion of Results}

As mentioned above, all results will be interpreted with caution, in light of the significant differences observed between the alt+codes/word list group and the handwriting/paragraph group on the pretest.

Significant differences were observed between each typing group and the handwriting group on the Immediate Posttest Recognition task, suggesting that typing did lead to better recall, but that amount of psychomotor movement did not lead to the increased recall. From the graph (Figure 2), it appears that the significant interaction effect of treatment group and presentation format is likely attributable to the significant differences observed between groups on the pretest; the handwriting/paragraph group's score was the lowest, while the other paragraph groups' scores were slightly above their word-list counterparts.

On the Immediate Posttest Dictation task, there was a significant difference between the presentation formats, along with a significant interaction. Considering the nature of the dictation exercises, these results suggest that the paragraph group's task was simply more difficult. However, in the graph (Figure 3 ), it is evident that within the paragraph group, the alt+codes/paragraph group outperformed the function keys/paragraph and handwriting/paragraph group, while all three treatment groups in the word list condition performed rather similarly. This suggests that the effects observed by Gascoigne (2000, 2006a, b), which were not obtained by Sturm (2006) or Sturm and Golato (in press) may be attributable to the use of a paragraph (Gascoigne) rather than a word list (Sturm). Furthermore, the difference between treatment groups approached significance $(p=.064)$; further research may in fact reveal a main effect of typing vs. handwriting.

From the results of the Immediate Posttest Dictation and Recognition, hypothesis 1a is partially supported; typing led to better ability to recognize correctly placed accent marks, but the results for accurate placement on a dictation task only approached significance.

On the two Delayed Posttest measures, there were no significant differences observed, except between presentation formats on the Delayed Posttest Dictation task. This result supports the suggestion that the paragraph group simply had a more difficult task on the dictation exercise. The results of both Delayed 
Posttest measures suggests that there are no long-term effects of treatment group or presentation format on learning/recall of accent mark placement in L2 French.

Systematically, there were no significant differences observed between the two typing groups (function keys and alt+codes) on any measure. Thus, hypothesis $1 \mathrm{~b}$ is not supported.

Hypothesis 2 is cautiously supported, in that the word list group did perform significantly better on the dictation tasks, but not on the recognition tasks. As discussed above, this is likely an effect of task difficulty, rather than an actual difference in learning.

The above analyses illuminate a plausible reason for the differences in the results found by Gascoigne (2000, 2006a,b) Sturm and Golato (in press) and Sturm (2006). The results from these previous studies, along with the present study, suggest that the differences between treatment groups will only be observed when target items are practiced and tested in a paragraph format. This would suggest that paragraph-level discourse (or possibly even sentence-level; this would require future research to explore) will afford more benefits to students when typed, although it would appear that students need not be tied to a particular method for producing accented letters when typing. In regards to ecological validity, typing paragraph- or sentence-level discourse is a more common classroom (and real-world) activity than typing a word list. In other words, typing only appears to have an effect on learning accent mark placement when one is typing longer discourses, but writing word-level discourse is hardly a goal of the proficiency-oriented classroom.

It is perhaps the ecological validity of typing or writing material in a paragraph rather than a word list that led to these results. Copying a word list may have seemed a mindless activity to the group who was asked to do so, and their awareness of forms or motivation in the activity may have been lower across the board. On the other hand, copying material in longer discourse is, as discussed above, a more real-world activity, and the participants' awareness of forms may have differed by treatment group; the handwriting group would have concentrated less intensely than those who were asked to type.

However, it is unfortunately possible that the significant differences observed within the are due to the initial difference between groups on the pretest. The graphs used to illustrate the interactions illustrates this quite clearly: in Figures 2, 3, 4, and 5, the group mean for the HW/paragraph group is considerably lower than the mean for the other groups. Without Gascoigne's $(2000,2006 a, b)$, Sturm and Golato's (in press) and Sturm's (2006) results, it would be difficult to make any claim on the effects within the paragraph group. Yet those results do exist, and do support the suggestion that the effect is real. In order to more solidly support the above suggestion about differences emerging between participants who practice target items in a paragraph, future research is needed.

The results of the delayed posttests are likely due to the fact that participants did not know the words they were asked to practice. Specifically, they had not been taught the meanings of the words chosen for this study. Gascoigne had adapted her paragraph from a beginning textbook (C. Gascoigne, personal communication, October 21, 2003) and assumed her participants would be able to understand the words (C. Gascoigne, personal communication, September 11, 2007). In fact, Sturm (2006) had found a significant difference within groups on their performances on Gascoigne-Lally's (2000) words and the words chosen for her study; although participants were exposed to her words twice and to GascoigneLally's (2000) only once, they performed better on Gascoigne-Lally's (2000) words. Long-term retention, according to Craik and Lockhart (1972), depends on encoding, and perhaps verbal material cannot be encoded without meaning, although nonsense words have been used in many studies, including one reviewed for this study (Cohen and Wickland 1990).

These results are partially supported by Schneider, Healy, and Bourne (1998) and Schneider, Healy, Ericsson, and Bourne (1995), who suggested that simple contexts (i.e., a word list) lead to better short- 
term recall than a complex context (i.e., a paragraph) but that long-term recall is better when material has been practiced with higher contextual interference. However, according to their results, the paragraph group should have outperformed the word list group on the delayed posttests, which was not the case. In this study, it must be reiterated, practice consisted of only one session, which was not enough to lead to long-term retention.

More likely, the paragraph in this study provided sufficient contextual interference to impede participants' ability to retain accent marks. Contextual interference in this case refers to both the environment of the paragraph and the difficulty of the paragraph carrying the words chosen for this study. In other words, it was a combination of not understanding the meaning of the words and the length of the paragraph. The word list group did not have to contend with the paragraph and could thus devote more attentional resources (cf. Schmidt 1995, 2001; Robinson 1995, 2003) to learning the accents. Chaudron (1985) describes the increased degree of comprehension, encoding, and recoding involved in listening and responding to a dictation task. Schneider, Healy, Ericsson, and Bourne (1995) and Schneider, Healy, and Bourne (1998) described the phenomenon of contextual interference and its effect on immediate recall.

As for the recognition task, it was simply easier for all participants than the dictation task. The dictation task involved two modalities (visual and aural) and required production (of a kind; participants were not asked to produce the target words spontaneously) while the recognition task asked them only to choose. The recognition task also had a limited number of possible answers; anyone should have been able to score $25 \%$ by simply guessing. Furthermore, it has been long established in L 2 teaching and learning that comprehension and receptive/passive skills (e.g., recognizing correctly spelled forms) develop more quickly than productive skills (such as writing a dictated text).

\subsection{Overall Conclusions}

First, it appears that typing does lead to better immediate recall of accent marks in L2 French, although this statement must be made cautiously, with respect to the finding that the alt+codes/word list group and handwriting paragraph group were not equivalent at the outset of the study. This supports Gascoigne's (2000, 2006a, b) research, but contradicts Sturm and Golato's (in press) and Sturm's (2006) work. However, from examining the paragraph and word list format groups separately, it is suggested that Sturm and Golato (in press) and Sturm (2006) did not find results due to their use of word lists, rather than paragraphs (Sturm and Golato in press) or paragraphs alone (Sturm, 2006). Future research, including replication studies, to add more support to this idea is certainly warranted.

It is important to mention here that although it is suggested by these results that typing is better than handwriting for immediate recall of accent marks, this effect does not last. Gascoigne (2000, 2006a, b) did not look at long-term effects; Sturm (2006) and Sturm and Golato (in press) did not find any long-term (one week later) effects.

Second, it appears that, as mentioned above, a paragraph is a more appropriate format for testing this phenomenon. As discussed above, for participants who were exposed to and practiced the words chosen for this study in a word list format, results were not systematic; rarely did the treatment groups' mean score rank in the expected order of alt + codes $>$ function keys $>$ handwriting, while the treatment groups in the paragraph group consistently did.

Third, it does not appear that the extra psychomotor movement in typing is the factor that led to increased recall. Looking back at Schmidt's $(1990,1995,2001)$ and Robinson's $(1995,2003)$ discussion of attention, awareness, and noticing, it seems that these factors in language learning may contribute to the effects observed. Future research might look at attention, awareness, and noticing and their contributions to the acquisition of accent marks in L2 French. 


\subsection{Limitations of this Study}

This study was designed to investigate whether psychomotor movement is a factor contributing to better recall of accent marks from typing target items rather than writing them by hand. It achieves this objective by quantifying movement between two typing conditions (one-stroke versus multiple keystrokes). A handwriting group was included to confirm Gascoigne's (2000, 2006a, b) findings that typing does lead to better recall of accent marks in L2 French.

There are, however, some limitations related to the materials that must be mentioned. First, as discussed above, the paragraph constructed from target words chosen for this study was difficult for participants However, it does have an advantage over Gascoigne's (2000, 2006a, b) paragraph, in that the words were chosen according to the strict guidelines described above. Gascoigne (2000, 2006a, b) adapted a text from the beginning textbook used in her classes for her research. However, this led to words being used in the study that were formally presented and/or frequently used in class (français, à), cognates of English words (opéra, télévision), or proper names (André, Fréderic).

There were, in addition, a few limitations of the design of the study which bear mentioning. First, there was only one practice or training session; this limited exposure to the words chosen for this study and their orthography. Second, the delayed posttests were administered only one week after treatment; this is less problematic than it could have been, as there were no significant differences observed on these measures and therefore no reason to conclude that there were long-term effects of treatment.

Finally, participants were not provided with translations of the words chosen for this study. This may have impeded their ability to learn the orthography of the words, as they did not have any way to acquire the meaning. Future researchers may want to continue using words that are unknown to the participants, but provide word meanings via images. The idea that knowing the meaning of the word will facilitate recall is supported by Hulme, Maughan, and Brown (1991), who found that learners' working memory for foreign words (in that case, Italian), increased when they had studied L1 translations.

\subsection{Final Conclusions}

As acquisition of a word in an L2 includes its orthography, L2 French and its wide use of accents present a special challenge for learners whose L1, such as English, does not feature accent marks. This study indicates that accent marks are better recalled when target items are typed, rather than written by hand, and that this effect only happens when target items are practiced in paragraph form. The results, however, do not support Gascoigne-Lally's (2000) post-hoc hypothesis, that the extra psycho-motor movement involved in typing led to the increased recall. 


\section{References}

Amon, E., Muyskens, J.A., and Omaggio Hadley, A.C. $(2004,2008) . V i s-\grave{a}-v i s, 3^{\text {rd }}$ ed, $4^{\text {th }}$ ed. New York : McGrawHill.

Bloemsaat, G., Van Galen, G.P., and Meulenbroek, R. G. J. (2003). Lateralized effects of orthographical irregularity and auditory memory load on the kinematics of transcription typing. Psychological Research, 67, 123-133.

Chaudron, C. (1985). Intake: on models and methods for discovering learners' processing of input. Studies in Second Language Acquisition, 7, 1-14.

Cohen, M. R. and Wickland, D. A. (1990). Component abilities of spelling, memory, and motor skill in novices' transcription typing. Perceptual and Motor Skills, 70, 19-31.

Coniam, D. (1998). Interactive evaluation of listening comprehension: How the context may help. Computer Assisted Language Learning, 11, 1, 35-53.

Craik, F. I. M. and Lockhart, R. S. (1972) Levels of processing: A framework for memory research. Journal of Verbal Learning and Verbal Behavior 11, 671-84.

Craik, F. I. M. and Tulving, E. (1975) Depth of processing and the retention of words in episodic memory. Journal of Experimental Psychology: General 104, 269-94.

Cunningham, A. E. and Stanovich, K. E. (1990) Early spelling acquisition: Writing beats the computer. Journal of Educational Psychology, 82, 1, 159-62.

Gascoigne, C. (2006a). Explicit input enhancement: Effects on target and non-target aspects of second language acquisition. Foreign Language Annals, 39, 4.

Gascoigne, C. (2006b). Toward an understanding of incidental input enhancement in computerized L2 environments. CALICO Journal, 24, 1.

Gascoigne-Lally, C. (2000). The effect of keyboarding on the acquisition of diacritical marks in the foreign language classroom. The French Review 73, 5, 899-907.

Heift, T. (2003) Drag or type, but don't click: A study on the effectiveness of different CALL exercise types. Revue canadienne de linguistique appliquée/Canadian Journal of Applied Linguistics, 6, 1, 69-85.

Hulme, Maughan, and Brown (1991). Memory for familiar and unfamiliar words: Evidence for a long-term memory contribution to short-term memory span. Journal of Memory and Cognition, 30, 685-701.

John, B. E. (1996). TYPIST: A theory of performance in skilled typing. Human-Computer Interaction, 11, 321-355.

Postman, L., Thompson, B. A., and Grey, W. D. (1978) The interpretation of encoding effects in retention. Journal of Verbal Learning and Verbal Behavior 17, 681-705.

Robinson, P. (1995). Attention, memory, and the "noticing" hypothesis. Language Learning, 45, 2, pp. 283-331.

Robinson, P. (2003) Attention and memory during SLA. In C.J. Doughty and M. Long (Eds.) The Handbook of Second Language Acquisition (pp. 631-678). Malden, MA: Blackwell Publishing.

Schmidt, R.W. (1990). The role of consciousness in second language learning. Applied Linguistics, 11, pp. 129-158.

Schmidt, R. (1995). Consciousness and foreign language learning: A tutorial on the role of attention and awareness in learning. In R. Schmidt (Ed.), Attention and Awareness in Foreign Language Learning (pp. 1-63). Honolulu: University of Hawai'i Press.

Schmidt, R. (2001). Attention. In P. Robinson (Ed.), Cognition and Second Language Instruction. Cambridge : Cambridge University Press.

Schmidt, R.W. and Frota, S.N. (1986) Developing basic conversational ability in a second language : A case study of an adult learner of Portuguese. In R.R. Day (Ed.), Talking to Learn: Conversation in Second Language Acquisition (pp.237-327). Rowley, MA: Newbury House Publishers. 
978-2-7598-0534-1, Paris, 2010, Institut de Linguistique Française

Psycholinguistique et acquisition

DOI $10.1051 / \mathrm{cmlf} / 2010032$

Schneider, V.I., Healy, A.F., Ericsson, K.A., and Bourne, L.E., Jr. The effects of contextual interference on the acquisition and retention of logical rules. In A.F. Healy and L.E. Bourne, Jr. (Eds.), Learning and memory of knowledge and skills: Durability and specificity (pp. 95-131). Thousand Oaks, CA: Sage.

Schneider, V.I., Healy, A.F., and Bourne, L.E., Jr. (1998) Contextual interference effects in foreign language vocabulary acquisition and retention. In A.F. Healy and L.E. Bourne (Eds.), Foreign Language Learning: Psycholinguistic Studies on Training and Retention. Mahwah, NJ: Lawrence Erlbaum Associates.

Sturm, J. (2006). The effect of keyboarding and presentation format on the recall of accent marks in L2 Learners of French. Working Papers in TESOL and Applied Linguistics, 6, 2.

Sturm, J. and Golato, P. (in press). The effect of the number of keystrokes on the acquisition of diacritical marks in L2 learners of French. To be published in the proceedings of the $6^{\text {th }}$ UNTELE Colloque.

Tulving, E. (2000). Introduction to memory. In M. S. Gazzaniga (Ed.) The New Cognitive Neurosciences, $2^{\text {nd }}$ Ed. (pp. 727-732). Cambridge, MA: MIT Press.

Vaughn, S., Schumm, J. S., and Gordon, J. (1993) Which motoric condition is most effective for teaching spelling to students $\quad$ with and without learning disabilities? Journal of Learning Disabilities 26, 3, 191-8. 


\section{Acknowledgments}

The author wishes to thank Peter Golato, Melissa Bowles, Zsuzsanna Fagyal, Andrea Golato, and Alice Omaggio Hadley for their contributions to this work, Valerie Wust for her thoughtful, insightful, and clear comments on the manuscript, and the anonymous reviewers for their comments. All errors that remain are mine.

\footnotetext{
${ }^{1}$ Perception of letters (Cooper 1983, p. 8).

${ }^{2}$ Storage of letters about to be typed (Cooper 1983, p. 10).

${ }^{3}$ Process of physically moving fingers toward appropriate keys (Cooper 1983, p. 14).

${ }^{4}$ System of verifying typed text (Cooper 1983, p. 14).

${ }^{5}$ Mental system overseeing all steps of typing process (Cooper 1983, p. 20).
} 